\title{
Study on accuracy assessment of DEM in the marsh using with interferometric PALSAR, Sentinel-1A and TerraSAR-X images
}

\author{
FU Bolin ${ }^{1,2}$, LI Ying ${ }^{3}$, GAO Ertao ${ }^{1,2}$, FAN Donglin ${ }^{1,2}$, LOU PEIQING $^{1,2}$ \\ (1.College of Geomatics and Geoinformation, Guilin University of Technology, Guilin 541004, \\ China; 2. Guangxi Key Laboratory of Spatial Information and Geomatics, Guilin 541004, China; 3. \\ Northeast Institute of Geography and Agroecology, Chinese Academy of Sciences, Changchun
} 130102, China)

KEY WORDS: Marsh, DEM, InSAR technique, Accuracy validation, Interferometric coherence difference

\begin{abstract}
:
To conserve and manage wetland resources, it is important to monitor hydro-geomorphic condition. In this paper, the interferometric SAR images of L-band ALOS-1 PALSAR, C-band Sentinel-1A and X-band TerraSAR were selected to produce DEM of wetland area in the Honghe National Nature Reserve using the InSAR technique. 111 testing points randomly selected from the 1:10000 topographic map were utilized to evaluate accuracy of remote-sensing based DEM. Finally, the interference coherence difference of wetland vegetation among three different wavelengths was compared and analyzed. The results showed that The DEM of wetland area produced by L-band ALOS-1 PALSAR interferometric images was in good agreement with the 1:10,000 topographic map data. The elevation value with the difference less than 3 meters account for over $76 \%$ of all testing points. The coherence coefficient of wetland calculated from PALSAR images was higher than Sentinel-1A and TerraSAR images. The coherence coefficient among wetland vegetation types was significantly different. The distribution area of forest and shrub-grass vegetation had a larger coherence coefficient than shallow-water marsh vegetation area and deep-water marsh vegetation area.
\end{abstract}

\section{INTRODUCTION}

Wetland is one of the most important and valuable ecosystems on earth, known as the "kidney of the earth", which provides a lot of ecological functions and service values, such as flood storage, drought prevention, water quality purification, climate regulation and biodiversity maintenance (Zhang et al., 2010; Kate et al., 2012; Zhang et al., 2013). However, extensive loss of wetlands has occurred in many countries throughout the world under human disturbance and climate change. According to incomplete statistics, about $57 \%$ of wetlands area of the world have been transformed or disappeared (Davidson et al., 2014). The elevation data of wetlands is essential basic data for estimating water level and ecological water demand, monitoring changes of groundwater level and surface water level, so timely updating DEM plays a crucial role in wetland protection and rational development (Xie et al., 2011; Liu et al., 2009; Harvey et al., 2009).

In situ floristic filed surveying and data collection can be expensive, labor intensive and even dangerous, due to difficulties of navigating wetlands. Meanwhile, spatial density and time sampling rate of field measurements is insufficient to produce high accuracy DEM data of wetland. Remote sensing provides a practical means in topographic survey of wetland to inform management. In particular, repeated coverage of remote sensing data offer the capability for monitoring spatial distribution of wetland vegetation over time. Optical stereo pairs derived from CCD camera for photographic measurement is used to calculate three-dimensional information of wetland, while this method is especially vulnerable to weather conditions (Zhang \&Yuan, 2009). Airborne LIDAR point cloud data also provides a fast and efficient way to extract wetland DEM, but this approach achieves wide range observations with high cost and complicated data processing (Liu, 2008). With its all-weather, all-time, high-precision and large-area observation capabilities, Interferometric Synthetic Aperture Radar (InSAR) technique has been used in surface deformation monitoring, regional DEM extraction and wetland water level change monitoring (Wang et 
al., 2007)

Wdowinski (2008) utilized to 1993-1996 L-band JERS-1 SAR data to study water level changes in Everglades wetlands, and demonstrated that the high level change enables accurate estimation of the wetland InSAR technique, which lies in the ranges of 5-10 cm. Hong (2010) present an InSAR technique called Small Temporal Baseline Subset (STBAS) with two-year long Radarsat-1 data acquired during 2006-2008 over the Water Conservation Area in the Everglades wetlands, south Florida (USA) for monitoring absolute water level time series. Xie (2013) used VV polarization C-band ENVISAT ASAR and $\mathrm{HH}$ polarization L-band ALOS PALSAR data in conjunction with synchronous field measurements to evaluate the potential to detect water level changes of natural wetlands in Yellow-River Delta. Sefercik (2014) used TerraSAR-X (TSX) high resolution Spotlight (HS) images to produce high-resolution interferometric DEM in a part of Istanbul urban area. In conclusion, InSAR technique has been widely used in wetland water level monitoring, and achieved centimeter-level monitoring accuracy. However, previous studies focus on extracting DEM based on InSAR in urban areas. There has been lack of relevant researches on (1) whether DEM extraction based on InSAR can be used to extract wetland DEM, and (2) whether the accuracy of remotesensing produced DEM varies with SAR data of different wavelengths.

In this study, the InSAR technique was used to extract the DEM for wetland area in the Honghe National Nature Reserve (HNNR) of Northeast China. The objective of this study was to: (1) evaluate the accuracy difference of three wavelengths InSAR-based DEM, and randomly select 111 points from 1:10,000 topographic map for accuracy verification; (2) compare and analyze the interference coherence differences among wetland vegetation for different SAR wavelengths.

\section{STUDY AREA AND DATA SOURCE}

\subsection{Study area}

Honghe National Nature Reserve (HNNR) is located in the hinterland of Sanjiang plain in Heilongjiang province (47 $\left.42^{\prime} 18^{\prime \prime N} \sim 47^{\circ} 52^{\prime} 07^{\prime \prime N}, 133^{\circ} 34^{\prime} 38^{\prime \prime} \mathrm{E} \sim 133^{\circ} 46^{\prime} 29^{\prime \prime} \mathrm{E}\right)$, at the junction of Tongjiang city and Fuyuan city, covering an area of 21,835 hectares (Figure 1). HNNR is a cold temperate continental monsoon climate with four distinct seasons and six months of freezing period. The average annual temperature is $1.9^{\circ} \mathrm{C}$ and the annual precipitation is $585 \mathrm{~mm}$. HNNR is the miniature and typical representative of the whole original freshwater marshes in Sanjiang plain and even the whole Northeast China. It is also one of the 36 existing international wetlands in China. There are four vegetation types, including island-forest, shrub, meadow and swamp vegetation in the study area, which circle around the pond and river.

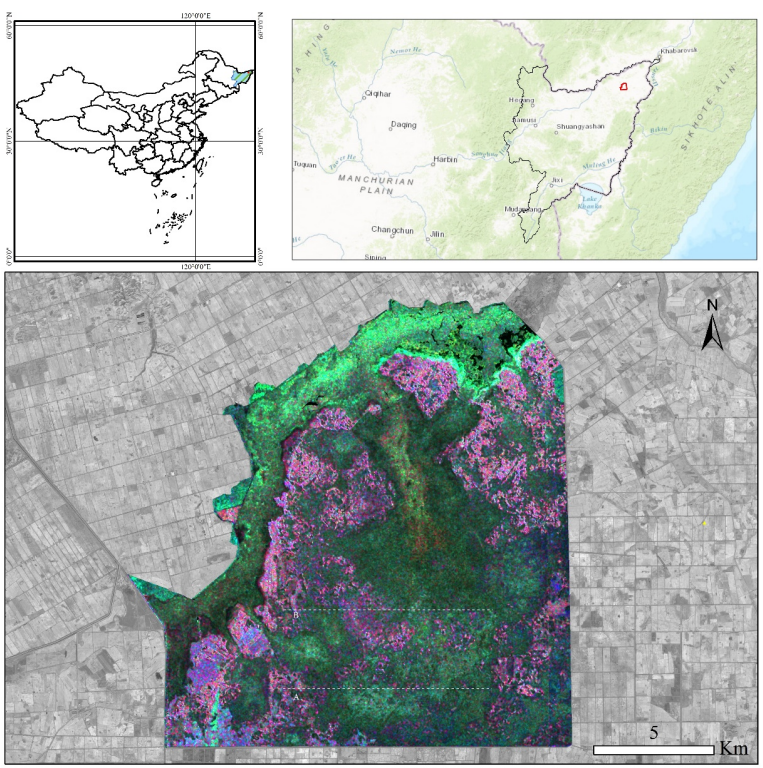

Figure 1 Location of the study area, The false color image was derived from the RGB combination of C-band Radarsat-2

Cloude\&Pottier H/A/alpha polarization decomposition parameters

\subsection{Data source}

In this paper, three interferometric SAR data pairs with different wavelengths are selected: May 28 and June 8, 2016 $\mathrm{X}$-band HH polarization TerraSAR single look complex (SLC) data, October 4 and October 16, 2015 C-band VV polarization of Sentinel-1A IW model SLC data, September 7 and October 23, 2007 L-band HH polarization ALOS-1 PALSAR fine pattern SLC data. ALL SAR images completely covered the study area, and specific imaging parameters were shown in Table 1. Additional data included 1:10,000 topographic map with $1 \mathrm{~m}$ elevation interval developed by the Chinese National Administration of Surveying, Mapping and Japan Aerospace Exploration Agency generated ALOS World 3D DEM data at 30 $\mathrm{m}$ spatial resolution (https://www.eorc.jaxa.jp/ALOS/en/ aw3d30/data/index.htm). 


\begin{tabular}{cccc}
\hline & TerraSAR & Sentinel-1A & PALSAR \\
\hline wavelength & $\mathrm{X}$ & $\mathrm{C}$ & $\mathrm{L}$ \\
Polarization & $\mathrm{HH}$ & $\mathrm{VV}+\mathrm{VH}$ & $\mathrm{HH} / \mathrm{HH}+\mathrm{HV}$ \\
Incidence angle $\left(^{\circ}\right)$ & 44.47 & 33.64 & $38.71 / 23.1$ \\
Spatial resolution $(\mathrm{m})$ & $2.52 \times 3.3$ & $4.66 \times 13.94$ & $9.37 \times 18.36 / 21.6 \times 3.76$ \\
Repetition cycle(days) & 12 & 12 & 46 \\
\hline
\end{tabular}

Table 1 Characteristics of three kinds of SAR data used in this study

\section{METHODS}

The main data processing of InSAR technique to extract DEM of wetland included baseline estimation of interferometric SAR image pairs, master and slave image co-registration, interferogram generation, flatten phase elimination, adaptive filtering and coherence calculation, phase unwrapping, orbit refinement and Re-flattening, phase to height conversion and geocoding to generate DEM.

\subsection{Baseline estimation and image co-registration}

Baseline estimation is the premise of extracting DEM using InSAR technique. Baseline estimation evaluates the quality status of two interferometric SAR image pairs by calculating normal baseline, critical baseline, Doppler displacement, $2 \pi$ ambiguity height and ambiguity displacement. When the imaging modes of two SAR images are inconsistent or the normal baseline exceeds the maximum value of the critical baseline, the coherence of two SAR images is lost and cannot be processed using InSAR technique (Gatelli et al., 1994). Table 2 describes the detailed parameters of baseline estimates for ALOS PALSAR, Sentinel-1A and TerraSAR. This paper selected sub-pixel registration method to register the master and slave images, and ensure two image registration error within 1/10 pixel.

\subsection{Interferogram generation and flat-earth phase removal}

The georeferenced master and slave SAR images pairs were processed for complex conjugate multiplication to generate the interference fringe pattern. The intensity of interferogram depicts topographic fluctuation. The phase in the interferogram is affected by the flatness effect, and the interference fringe presents a regular distribution in a flat and gentle fluctuations region. Figure 2 shown the interferogram of the study area using three SAR data.
The interferometric phase after eliminating flat phase can depict the phase difference between topography and reference plane, and reduce the difficulty of interferogram filtering and phase unwrapping with decreasing the fringe frequency of the interferogram. In this paper, ALOS World 3D DEM data is used to simulate the flat phase of the study area to eliminate the flat effect.

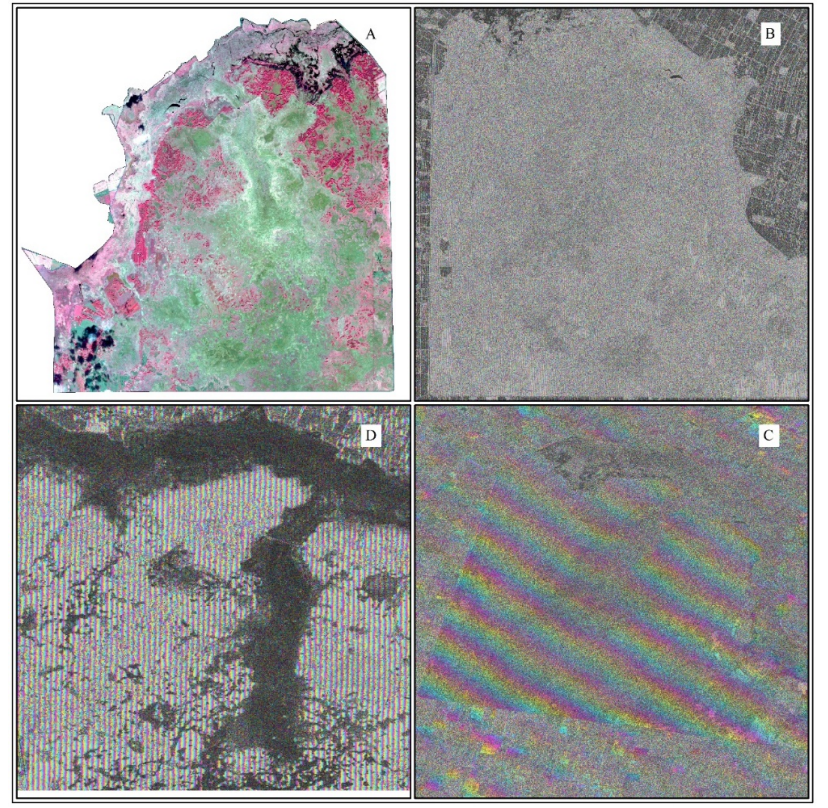

Figure 2 the interferogram of the study area using three SAR data: A was the RGB image derived from wavelet fusion of GF-1 multispectral image and $\mathrm{HH}$ polarization Radarsat-2 backscattering intensity data. $\mathrm{B}$ was the interferogram generated by X-band TerraSAR images; $\mathrm{C}$ was the interferogram generated by C-band Sentinel-1A images; $\mathrm{D}$ was the interferogram generated by L-band PALSAR images.

It can be seen from the Figure 2 that the interferometric fringe generated by TerraSAR is very dense with a large amount of phase noise, which the fringes derived from Sentinel-1A and PALSAR were relatively sparse. At the same time, the fringe produced by PALSAR images was significantly better than that of Sentinel-1A and TerraSAR with shorter wavelength. 


\begin{tabular}{|c|c|c|c|c|c|c|}
\hline Data sources & Acquisition time & $\begin{array}{c}\text { Normal } \\
\text { baseline (m) }\end{array}$ & $\begin{array}{c}\text { Time } \\
\text { baseline } \\
\text { (day) }\end{array}$ & $\begin{array}{c}\text { Doppler } \\
\text { displacement } \\
(\mathrm{Hz})\end{array}$ & $\begin{array}{c}2 \pi \\
\text { ambiguity } \\
\text { height(m) }\end{array}$ & Critical baseline (m) \\
\hline PALSAR & 2007/9/7 2007/10/23 & 1053.74 & 46 & 2.81 & 61.06 & $-9827.86 \sim 9827.86$ \\
\hline Sentinel-1A & 2015/10/4 2015/10/16 & 90.33 & 12 & 7.51 & 133.43 & $-4665.03 \sim 4665.03$ \\
\hline TerraSAR-X & $2016 / 5 / 28 \sim 2016 / 6 / 8$ & 302.05 & 12 & 49.43 & 25.12 & $-6147.21 \sim 6147.21$ \\
\hline
\end{tabular}

Table 2 the parameters of baseline estimation of three SAR image pairs

\subsection{Adaptive filtering and coherence calculation}

Phase noise in the interferogram are mainly derived from target scattering characteristics, image registration error, systematic thermal noise and data processing errors. Phase noise reduces the quality of the interferogram and increases the complexity of phase unwrapping, which directly affects the accuracy of the final generated DEM. Therefore, this study used adaptive Goldstein filter algorithm to eliminate phase noise in the interferogram (Goldstein \& Werner, 1998), and selected the maximum likelihood estimator to calculate the coherence coefficient, which indicated coherence status of study area (Figure 3).

It can be seen from Figure 3 that after adaptive Goldstein filtering and phase flattening, the interferometric fringe become more sparse and smooth in the study area with better coherence. The region of deep-water vegetation was obviously reduced the coherence due to water bodies and volume scattering, and the interferometric fringe was not clear and continuous.

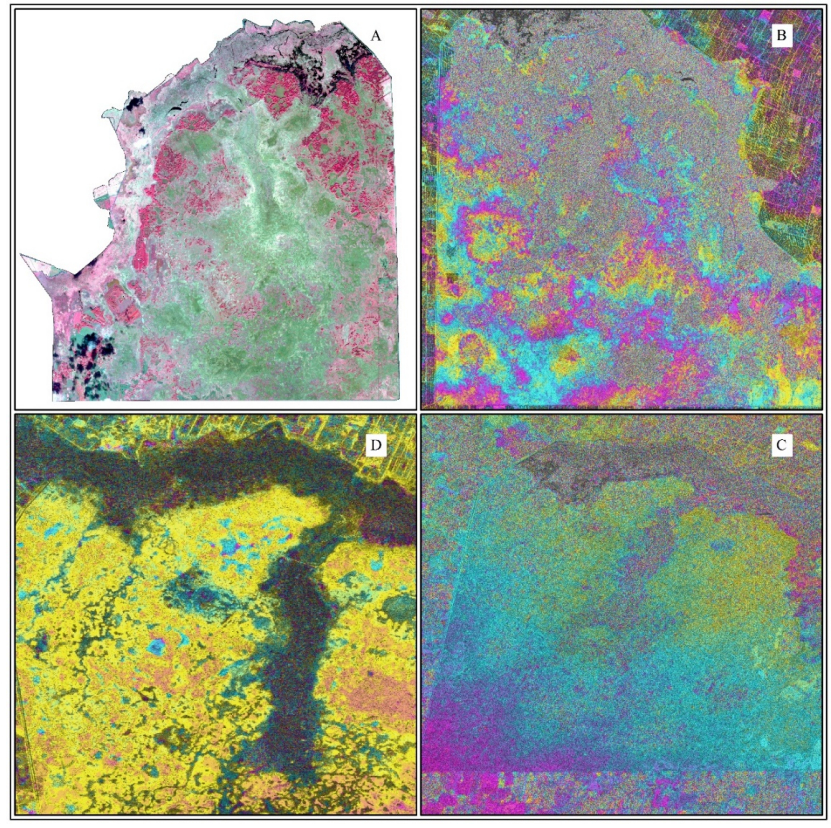

Figure 3 interferometric fringe after adaptive Goldstein filtering and phase flattening: A was the RGB image derived from wavelet fusion of GF-1 multispectral image and $\mathrm{HH}$ polarization Radarsat-2 backscattering intensity data; $B$ was the interferometric fringe generated by TerraSAR images; $C$ was interferometric fringe generated by Sentinel-1A images. D is the interferometric fringe produced by PALSAR images.

\section{4 phase unwrapping and orbit refinement and Re-flattening}

The phase value in the interferogram obtained by the complex conjugate multiplication is the principal value, which usually record the phase change with a cycle of 2 PI. It is necessary to unwrap phase and determine the real phase value between each pixel.

The distribution structure of complex vegetation types in HNNR determines that there are many discontinuous areas in the 
interferogram. The 3D Delaunay Minimum Cost Flow algorithm was used for phase unwrapping, which is more suitable for performing phase unwrapping in the wetland area. Therefore, the Minimum Cost Flow algorithm was adopted in this study to obtain the true phase value in the interferometric fringe by phase unwrapping, and the threshold of phase unwrapping was set between 0.12 and 0.15 by comprehensive consideration of overall coherence condition of the study area.

The conversion from unwrapping phase to surface elevation value required accurate baseline parameters, and need to execute orbital refinement for further accurately estimating geometric parameters and removing flatness effects. In this study, the ground control points within the uniform and high coherent areas of vegetation communities were selected for orbital refining and re-flattening. The root mean square error after correction was controlled within one pixel. The unwrapping phase after orbital refining and re-flattening was shown in Figure 4.

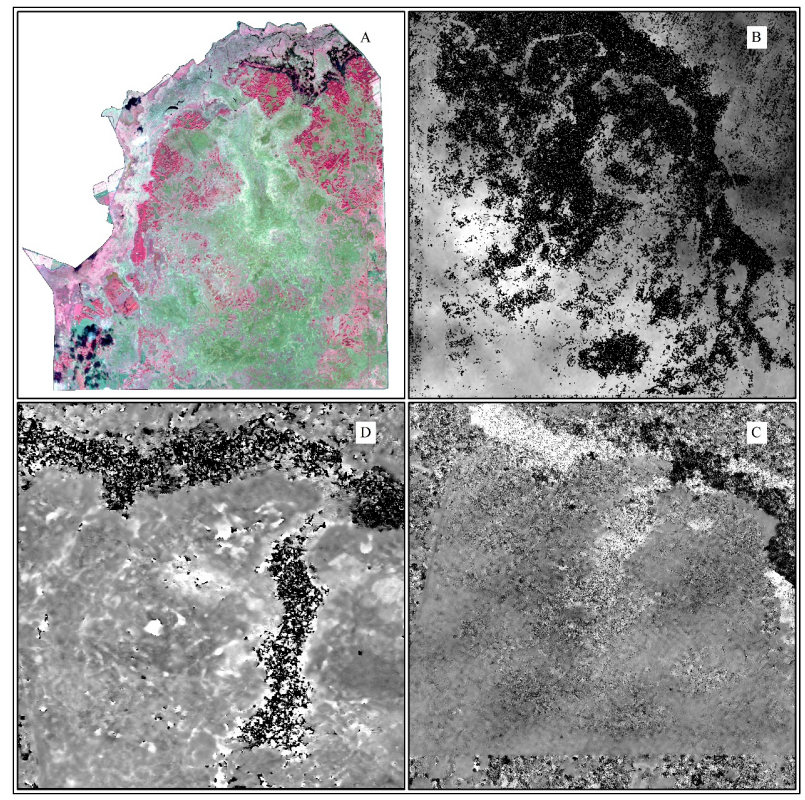

Figure 4 the unwrapping phase after orbital refining and re-flattening: A was the RGB image derived from wavelet fusion of GF-1 multispectral image and $\mathrm{HH}$ polarization Radarsat-2 backscattering intensity data. B was the unwrapping phase using TerraSAR images; $\mathrm{C}$ was the unwrapping phase using Sentinel-1A images; D was the unwrapping phase using PALSAR images.

\section{RESULTS}

\subsection{Accuracy assessment}

In order to validate the accuracy of InSAR-based DEM , $2501 \mathrm{~km} \times 1 \mathrm{~km}$ grid and 111 Random Points were generated using 'Fishnet' and 'Create Random Points' Toolbox in ArcGIS respectively in the study area. The random points and grid were executed spatially overlay with 1:10,000 topographic map, and ensured that there was only one random point with accurate elevation value in a grid. These points were taken as the accuracy validation data to evaluate the accuracy of DEM using InSAR technique. The accuracy difference between testing data and remote-sensing observation was statistically analyzed (Figure 5 and Table 3).

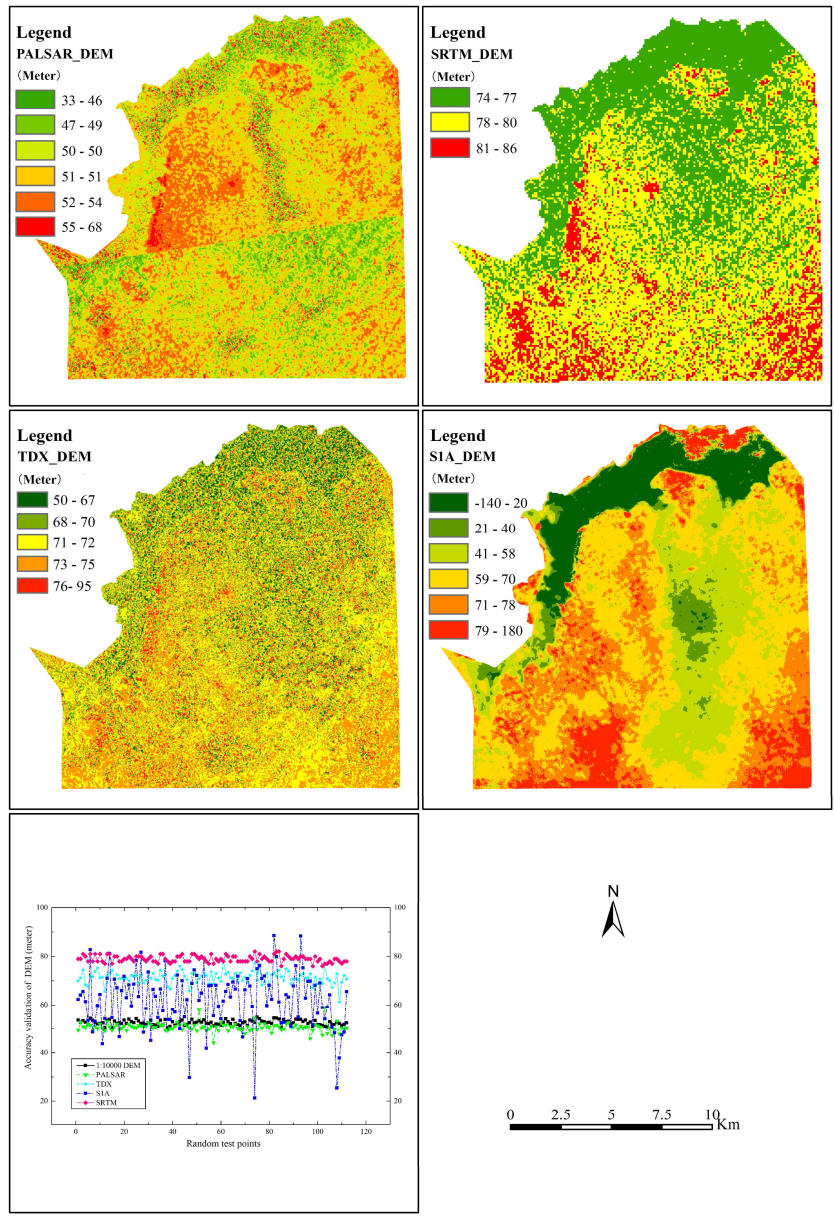

Figure 5 the DEM data of study area using three kinds of interferometric SAR data pairs

The DEM quality produced by InSAR technique was affected by volume scattering of wetland vegetation and water body (Figure 5). The region of deep-water swamp vegetation with low coherence produced poor elevation value with the large numerical differences from testing data. The accuracy of DEM in the study area produced by L-band PALSAR interferometric images is better than C-band Sentinel 1A, X-band TerraSAR interferometric images and $30 \mathrm{~m}$ SRTM DEM products, which had a good agreement with 1:10,000 topographic map. The elevation values derived from PALSAR images with the 
difference less than 3 meters account for $76.58 \%$ of the total testing points (Table 3 ).

\begin{tabular}{ccccccc}
\hline & \multicolumn{5}{c}{ The numerical difference distribution of InSAR technique and 1:10000 topographic map } \\
\cline { 2 - 7 } & $<1 \mathrm{~m}$ & $<3 \mathrm{~m}$ & $<5 \mathrm{~m}$ & $<10 \mathrm{~m}$ & $<20 \mathrm{~m}$ & $<30 \mathrm{~m}$ \\
\hline PALSAR & 24 & 85 & 108 & 111 & 111 & 111 \\
Sentinel-1A & 3 & 12 & 25 & 46 & 92 & 109 \\
TerraSAR-X & 0 & 0 & 0 & 1 & 75 & 111 \\
\hline
\end{tabular}

Table 3 the difference of DEM between InSAR technique and 1:10000 topographic map

\subsection{Coherence difference of wetland vegetation}

The coherent coefficient of wetland area (Figure 6) was calculated after the processing of orbit refining and Re-flattening. The coherence coefficient indicates the quality of the interferogram, and it can also quantitatively estimate the stability of the target phase in the two imaging processes of SAR Satellite. The coherence coefficient values is range from 0 to 1 , which is higher, the quality of interferogram is better. Figure 6 present the coherence coefficient generated by different interferometric SAR image pairs, and the coherence coefficient value corresponding to the profile line in Figure 8A was shown in Figure 7.

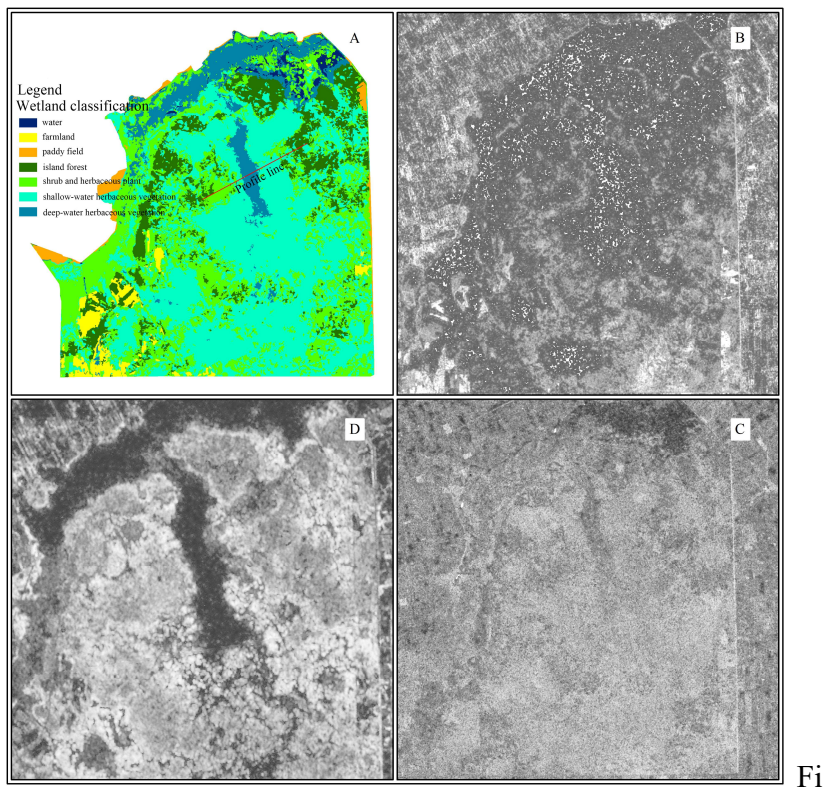

gure 6 Coherence coefficient of study area: A was the marsh wetland vegetation distribution map using ZY-3 and Radarsat-2 images. B was the coherence coefficient produced by TerraSAR; $\mathrm{C}$ was the coherence coefficient produced by Sentinel-1A. D was the coherence coefficient produced by PALSAR.

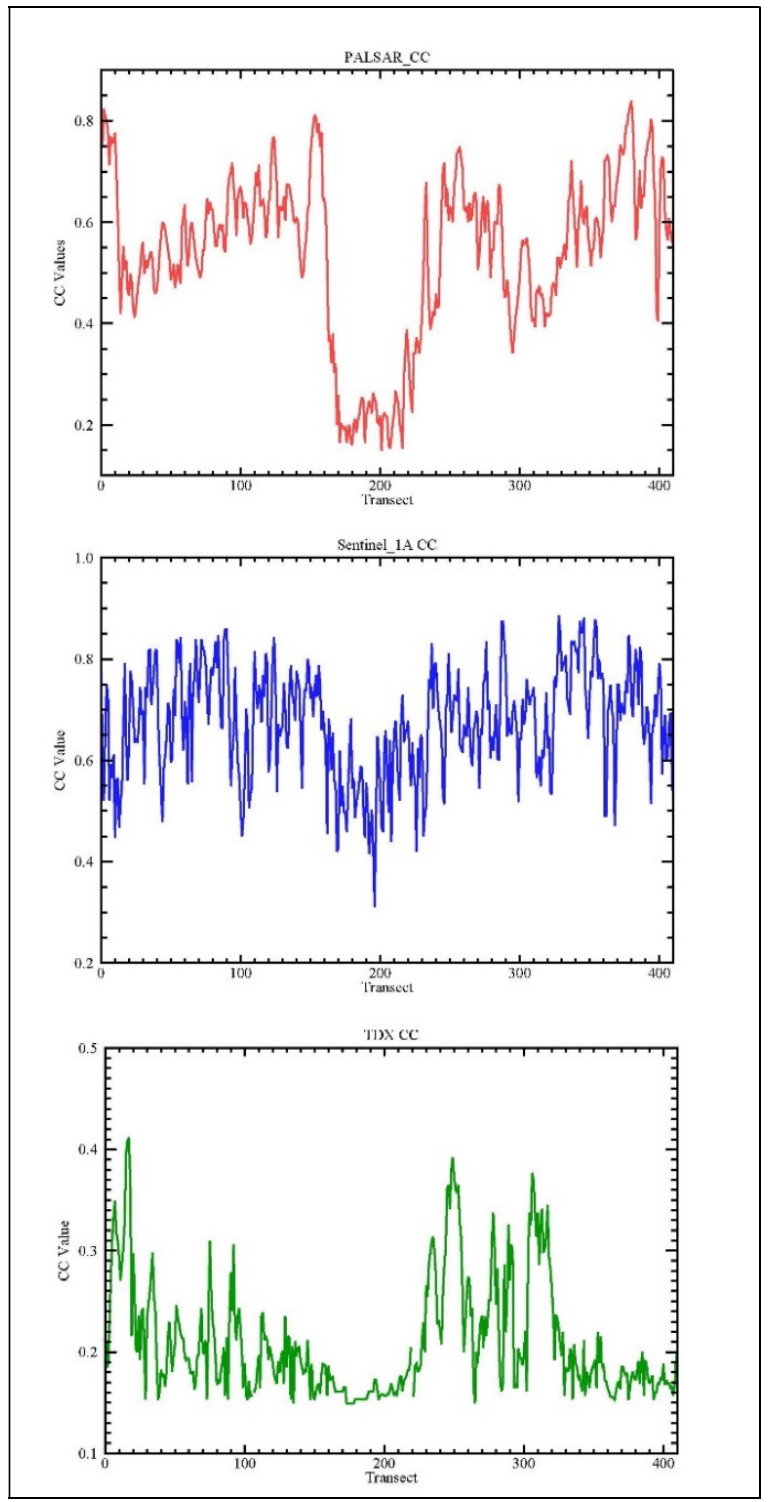

Figure 7 coherence coefficient value extracted from the profile line of Figure 6A: 'PALSAR CC' was the coherence coefficient value of PALSAR; 'Sentinel-1A CC' was the coherence coefficient value of Sentinel-1A. 'TDX CC' was the coherence coefficient value of TerraSAR. 
The coherence coefficient value of island-forest and shrub area was the highest, followed by shallow-water vegetation area, and the lowest was deep-water vegetation area. The main reason for the coherence difference of study area was that the change of wetland water level during the repetition cycle of two SAR images brought about the change of vegetation position and height in deep-water swamp area and part of shallow-water swamp area dominated by floating plants. From the coherence coefficient curves of L-band PALSAR and C-band Sentinle-1A, it can be seen that the coherence coefficient values of island-forest and shrub vegetation area achieved 0.6 0.8, while shallow-water swamp vegetation area was 0.4 0.6, and deep-water swamp vegetation area was the lowest with the range from 0.2 to 0.3 . Then the coherence coefficient curves extracted by X-band TerraSAR indicated that coherence coefficients in the vegetation areas of island-forests combined with shrubs and grasses achieved $0.3 \sim 0.4$, shallow-water vegetation areas were $0.2 \sim 0.3$, and the deep-water vegetation area were only $0.1 \sim 0.2$. The difference of coherence coefficient values in the same vegetation area indicated that L-band PALSAR data was more suitable for interference measurement of wetland, while X-band TerraSAR data was not suitable for interference measurement of swamp.

\section{CONCLUSION}

In this paper, three kinds of InSAR data with different wavelengths were used to extract the DEM of wetland area. Goldstein filter algorithm was utilized to eliminate phase noise produced by time and spatial baseline for improving the continuity of interference fringe and reducing the complexity of phase unwrapping. The Minimum Cost Flow method of 3D Delaunay was used for phase unwrapping, and the unwrapping threshold was between 0.12 and 0.15 . The control points in the uniform and high coherence of wetland area were selected for orbital refining and re-flattening, and the root mean square error after orbit correction was controlled within one pixel. The result of precision validation of DEM shown that L-band PALSAR was more suitable for interference measurement to extract the wetland DEM. The elevation values derived from PALSAR images with the difference less than 3 meters account for $76.58 \%$ of the total testing points, and shorter wavelength C-band Sentinel-1A and X-band TerraSAR due to temporal decoherence and wetland vegetation growth reducing DEM accuracy. Comparison of the difference of coherence coefficient values in the same vegetation area found that the coherence coefficient of
PALSAR is higher than the other two SAR data, which was more suitable for the interference measurement of wetlands area. Comparison the coherence coefficients of different wetland vegetation types found that the island- forests was the highest, while the deep-water vegetation areas was the lowest.

\section{ACKNOWLEDGMENT}

This study was funded by the National Natural Science Foundation of China (Grant No. 41801071), Natural Science Foundation of Guangxi (Grant No. 2018GXNSFBA281015), and Guilin university of technology scientific research Foundation (Grant No. GUTQDJJ2017096).

\section{REFERENCES}

Davidson N C. 2014. How Much Wetland Has the World Lost? Long-Term and Recent Trends in Global Wetland Area. Marine and Freshwater Research, 65(10):934-941.

Gatelli, F., Guamieri, A. M., Parizzi, F., Pasquali, P., Prati, C., \& Rocca, F. 1994. The wavenumber shift in sar interferometry. IEEE Transactions on Geoscience \& Remote Sensing, 32(4), $0-865$.

Goldstein, R. M., \& Werner, C. L.1998. Radar interferogram filtering for geophysical applications. Geophysical Research Letters, 25(21), 4035-4038

Harvey, J. W., Schaffranek, R. W., Noe, G. B., Larsen, L. G., Nowacki, D. J., \& O"Connor, B. L. 2009. Hydroecological factors governing surface water flow on a low-gradient floodplain. Water Resources Research, 45(3), n/a-n/a.

Hong, S. H., Wdowinski, S., Kim, S. W., \& Won, J. S.. 2010. Multi-temporal monitoring of wetland water levels in the florida everglades using interferometric synthetic aperture radar (InSAR). Remote Sensing of Environment, 114(11), 2436-2447.

Kate C. F., Warren B. C., Yang Z. Q.. 2016. Landsat-based monitoring of annual wetland change in the Willamette Valley of Oregon, USA from 1972 to 2012. Wetlands Ecology and Management, 24(1):73-92.

Liu X. 2008. Airborne LiDAR for DEM generation: some critical issues. Progress in Physical Geography, 32(1): 31-49.

Liu, Z., Volin, J. C., Owen, V. D., Pearlstine, L. G., Allen, J. R., \& Mazzotti, F. J. 2009. Validation and ecosystem applications of the eden water-surface model for the florida everglades. Ecohydrology, 2(2), 182-194.

Sefercik, U. G., Yastikli, N., \& Dana, I. 2014. Dem extraction in 
urban areas using high-resolution TerraSAR-X imagery. Journal of the Indian Society of Remote Sensing, 42(2), 279-290.

Wang Z. Y., Zhang J. X., Zhang Y. H. 2007. DEM extraction from techniques. Bulletin of Surveying and Mapping, (7):27-29+34

Wdowinski, S., Kim, S. W., Amelung, F., Dixon, T. H., Miralles-Wilhelm, F., \& Sonenshein, R. 2008. Space-based detection of wetlands $\backslash$ " surface water level changes from L-band SAR interferometry. Remote Sensing of Environment, 112(3), 681-696.

Xie, C., Shao, Y., Xu, J., Wan, Z., \& Fang, L. 2013. Analysis of alos palsar insar data for mapping water level changes in yellow river delta wetlands. International Journal of Remote Sensing, 34(6), 2047-2056.

Xie, Z., Liu, Z., Jones, J. W., Higer, A. L., \& Telis, P. A. 2011. Landscape unit based digital elevation model development for the freshwater wetlands within the arthur c. marshall loxahatchee national wildlife refuge, southeastern florida. Applied Geography, 31(2), 0-412.

Zhang L., Wang M. H., Hu J. 2010. A review of published wetland research, 1991-2008: Ecological engineering and ecosystem restoration. Ecological Engineering, 36(8):973-980.

Zhang S. W., Yan F. Q., Yu L. X., Bu K., Yang J. C., Chang . P., 2013. Application of Remote Sensing Technology to Wetland Research. SCIENTIA GEOGRAPHICA SINICA, 33(11):1406-1412.

Zhang L., Yuan F. 2009. Geometric Modeling of Optical Spaceborne Sensors and DEM Generation.GEOMATICS WORLD, (2):53-62+71. 